\title{
PENGARUH KEMAMPUAN MANAJEMEN, MOTIVASI FRANCHISE, BRAND IMAGE DAN PROMOTION STRATEGY TERHADAP KEBERHASILAN USAHA FRANCHISE (Studi Kasus : Primagama Indonesia Timur)
}

\author{
Yunita Primasanti ${ }^{1}$, Imam Djati Widodo ${ }^{2}$ \\ BATAN Yogyakartal) \\ Jl. Babarsari Sleman Yogyakarta \\ Magister Teknik Industri, Fakultas Teknologi Industri, Universitas Islam Indonesia ${ }^{2}$ \\ Jl. Kaliurang Km. 14,5 Sleman, Yogyakarta 55584 \\ E-Mail :yprimasanti@gmail.com ${ }^{1}$,Imam.djati.widodo@uii.ac.id ${ }^{2}$
}

\begin{abstract}
Enterprises that can be directly executed properly without having to market from the beginning is to buy products or services that have become, namely Franchise. It is the licensing of an overall business format in which the franchisor grants a license to a number of dealers or franchisee to market a product / service and conduct a business developed by franschisor using a name brand, Trademarks, specialist merchandising services and how to do business that the franchisor owns. This data analysis technique is by using quantitative technique with path analysis. Variable there are 6, which consists of Management Ability, Motivation Franchise, Brand Image and Promotion Strategy. These variables are called independent variables. Performance Franchise enter the dependent variable, while Franchise Cooperation entered variable factor. The sample in this research is 120 respondents, with data collection technique through questionnaire with likert scale. The result of this research is that the variable of Management Capability, Franchise Motivation, Brand Image and Promotion Strategy have direct influence to Franchise Cooperation, but have no direct effect on Knelan Franchise.
\end{abstract}

Keyword: Franchise, Management Ability, Motivation Franchise, Brand Image, Promotion Strategy.

\section{PENDAHULUAN}

\subsection{Latar Belakang Masalah}

Bentuk usaha franchise digambarkan sebagai perpaduan bisnis besar dan kecil, yaitu perpaduan antara energi dan komitmen individual dengan sumber daya dan kekuatan sebuah perusahaan besar (Sulistiyani, 2008: 64). Menurut Murti Sumarni (1998), franchise adalah pemberian lisensi atas suatu format bisnis secara keseluruhan, dimana pihak pemilik hak guna nama (franchisor) memberikan lisensi atas sejumlah penyalur atau penerima hak guna nama (franchisee) untuk memasarkan suatu produk / jasa dan melakukan bisnis yang dikembangkan oleh franschisor dengan menggunakan merk nama, merk dagang, merk jasa keahlian khusus dan cara melakukan bisnis yang memiliki oleh franchisor. Sedangkan International Franchise Association mengajukan definisi franchise adalah hubungan perjanjian antara franchisor dan franchisee, dimana franchisor menawarkan atau berkewajiban untuk memelihara kesinambungan kepentingan franchisee dalam hal pengetahuan, ketrampilan, pelatihan bidang bisnis franchise dan franchisee berhak beroperasi dengan nama dagang, atau format atau prosedur yang dimiliki dan di bawah pengawasan franchisor. Untuk kepentingan tersebut mengharuskan franchisee untuk melakukan investasi dengan modalnya (Sulistiyani, $2008: 65)$.

Beberapa franchise asing yang sukses di Indonesia misalnya McDonald's, Kentucky Fried Chicken, Bread Talk, Starbucks dan Pizza Hut. Dalam pengoperasiannya franchise asing tersebut menjual master franchise. Master franchise ini berhak untuk mengelola sendiri atau menjual kembali kepada franchisee pada suatu teritori 


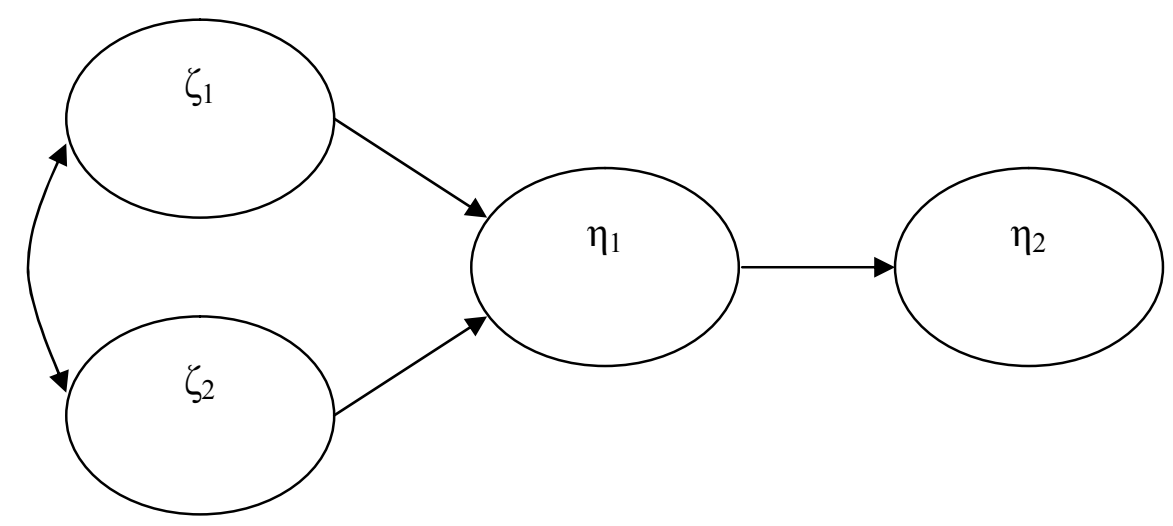

Gambar 1. Penggambaran Variabel Laten Eksogen dan Laten Endogen. (Sumber : Nawangsari $(2011: 34)$ )

tertentu, tergantung pada kesepakatan. Pertumbuhan bisnis franchise yang cepat di Indonesa merupakan peran serta dari merek merek franchise lokal seperti Primagama, Alfamart, Martha Tilaar, Roti Buana, Edward Forrer, Bogasari Baking Center dan berbagai nama lainnya. Merek - merek lokal ini diarahkan pemerintah untuk bernaung dibawah AFI (Asosiasi Franchise Indonesia) yang merupakan asosiasi resmi yang diakui pemerintah dalam bidang franchise (Sulistiyani, $2008: 66$ ).

Berdasarkan uraian latar belakang masalah serta studi kasus diatas, maka perlu diadakan penelitian tentang Pengaruh Kemampuan Manajemen, Motivasi Franchisee, Promotion Strategy dan Brand Image Terhadap Keberhasilan Usaha Franchise (Studi Kasus Pada Master Franchise Primagama Indonesia Timur).

\subsection{Landasan Teori}

\section{- Definisi Franchise}

Franchise adalah perikatan dimana salah satu pihak diberikan hak untuk memanfaatkan atau mengggunakan hak atas kekayaan intelektual atau penemuan atau ciri khas usaha yang dimiliki pihak lain dengan suatu imbalan berdasarkan persyaratan yang ditetapkan pihak lain tersebut dalam rangka penyediaan dan / atau penjualan barang atau jasa (Burhanuddin, 2009: 241).

\section{- Franchise Primagama}

Primagama adalah usaha jasa pendidikan (luar sekolah) dengan memiliki pasar yang sangat luas (siswa kelas SD, SLTP dan SMU) dan saat ini telah memiliki lebih 600 outlet diseluruh Indonesia serta 100.000 siswa setiap tahunnya. Prestasi Primagama dikenal dengan dimilikinya satu metode belajar Smart Solution yang sangat diminati para pelajar kita dan Life Skill Education sebagai added value bagi siswa dalam rangka mendukung program Kurikulum Berbasis Kompetensi (Adi Negara, 2008 : 85-86).

\subsection{Structural Equation Modeling (SEM)}

SEM adalah salah satu metode penelitian multivariate yang paling sering digunakan untuk penelitian dibidang ilmu sosial, psikologi, menejemen, ekonomi, sosiologi, ilmu politik, ilmu pemasaran, dan pendidikan. Berikut mengenai penulisan dan penggambaran variabel - variabel yang terdapat pada SEM (Nawangsari, 2011 : 34$36)$, pada gambar 1 .

Terdapat 2 variabel laten eksogen yaitu $\zeta_{1}$ dan $\zeta_{2}$. Terdapat 2 variabel laten endogen yaitu $\eta_{1}$ dan $\eta_{2}$. variabel laten eksogen dihubungkan dengan 2 anak panah $(\leftrightarrow)$ dan variabel endogen dihubungkan dengan 1 anak panah $(\rightarrow)$. 


\subsection{Analisis Structural Equation Model (SEM)}

Analisis Stuctural Equation Model bertujuan untuk mengestimasi beberapa persamaan regresi terpisah akan tetapi masing - masing mempunyai hubungan simultan atau bersamaan. Dalam analisis ini dimungkinkan terdapat beberapa variabel dependen, dan variabel ini dimungkinkan menjadi variabel independen bagi variabel dependen yang lainnya. Pada prinsipnya, model struktural bertujuan untuk menguji hubungan sebab akibat antar variabel sehingga jika salah satu variabel diubah, maka terjadi perubahan pada variabel yang lain. Dalam studi ini, data diolah dengan menggunakan Analysis of Moment Structure atau AMOS versi 16. Adapun rumus persamaan struktural dalam penelitian ini adalah sebagai berikut :

$\eta_{2}=\gamma_{1} \xi_{1}+\gamma_{2} \xi_{2}+\gamma_{3} \xi_{3}+\zeta_{1}$

$\eta_{2}=\gamma_{1} \xi_{1}+\gamma_{2} \xi_{2}+\gamma_{3} \xi_{3}+\eta_{1}+\zeta_{2}$

Keterangan :

$\xi_{1}=$ Kemampuan manjemen sebagai variabel eksogen (bebas) pertama.

$\xi_{2}=$ Motivasi franchise sebagai variabel eksogen (bebas) kedua.

$\xi_{3}=$ Promotion strategy sebagai variabel eksogen (bebas) ketiga.

$=$ Brand image sebagai variabel eksogen (bebas) keempat.

$\eta_{1}=$ Kerjasama franchisor dengan franchisee sebagai variabel laten endogen (terikat) kedua.

$\gamma_{1, \ldots 3}=$ Hubungan langsung variabel eksogen dengan endogen.

$\zeta_{1,2}=$ Measurement error (residual) endogen.

Pada prinsipnya, model struktural bertujuan untuk menguji hubungan sebab akibat antar variabel sehingga jika salah satu variabel diubah, maka terjadi perubahan pada variabel yang lain. Dalam studi ini, data diolah dengan menggunakan Analysis of Moment Structure atau AMOS versi 16. Analisis SEM memungkinkan perhitungan estimasi seperangkat persamaan regresi yang simultan, berganda dan saling berhubungan. Karakteristik penggunaan model ini yaitu :

1. Untuk mengestimasi hubungan dependen ganda yang saling berkaitan.

2. Kemampuannya untuk memunculkan konsep yang tidak teramati dalam hubungan, serta dalam menentukan kesalahan pengukuran dalam proses estimasi.

3. Kemampuannya untuk mengakomodasi seperangkat hubungan antara variabel independen dengan variabel dependen serta mengungkap variabel laten (Ghozali, 2005: 26).

\subsection{Metodologi Penelitian}

\section{- Kerangka Teori}

Usaha franchise apabila tidak dikelola dengan serius secara efektif dan efisien, bukan tidak mungkin apabila kelak waralaba yang dibangunnya akan gagal ditengah jalan. Fitriani (2009 : 87-88), mengemukakan hasil identifikasi faktor - faktor internal waralaba Primagama untuk mengurangi kelemahan serta ancaman yang dihadapi diantaranya produk yang inovatif dan berkualitas, manajemen yang profesional, promosi yang berkesinambungan, SOP yang matang dan kuat, financial yang kuat serta pertumbuhan outlet yang cepat. Sedangkan faktor - faktor eksternal diantaranya adalah paradigma masyarakat terhadap pendidikan, persaingan SPMB, kebijakan negara tentang sekolah gratis dan pemberian BOS serta dukungan pemerintah untuk perkembangan waralaba.

Dalam penelitian ini, hal pokok yang akan diuji dan kemudian disajikan dalam bentuk kerangka teori penelitian, adalah untuk analisis faktor internal (kemampuan manajemen, motivasi franchisee, promotion strategy dan brand image terhadap keberhasilan usaha franchise dengan metode structural equation modeling (SEM) (studi kasus pada Master Franchise Primagama Indonesia Timur). 


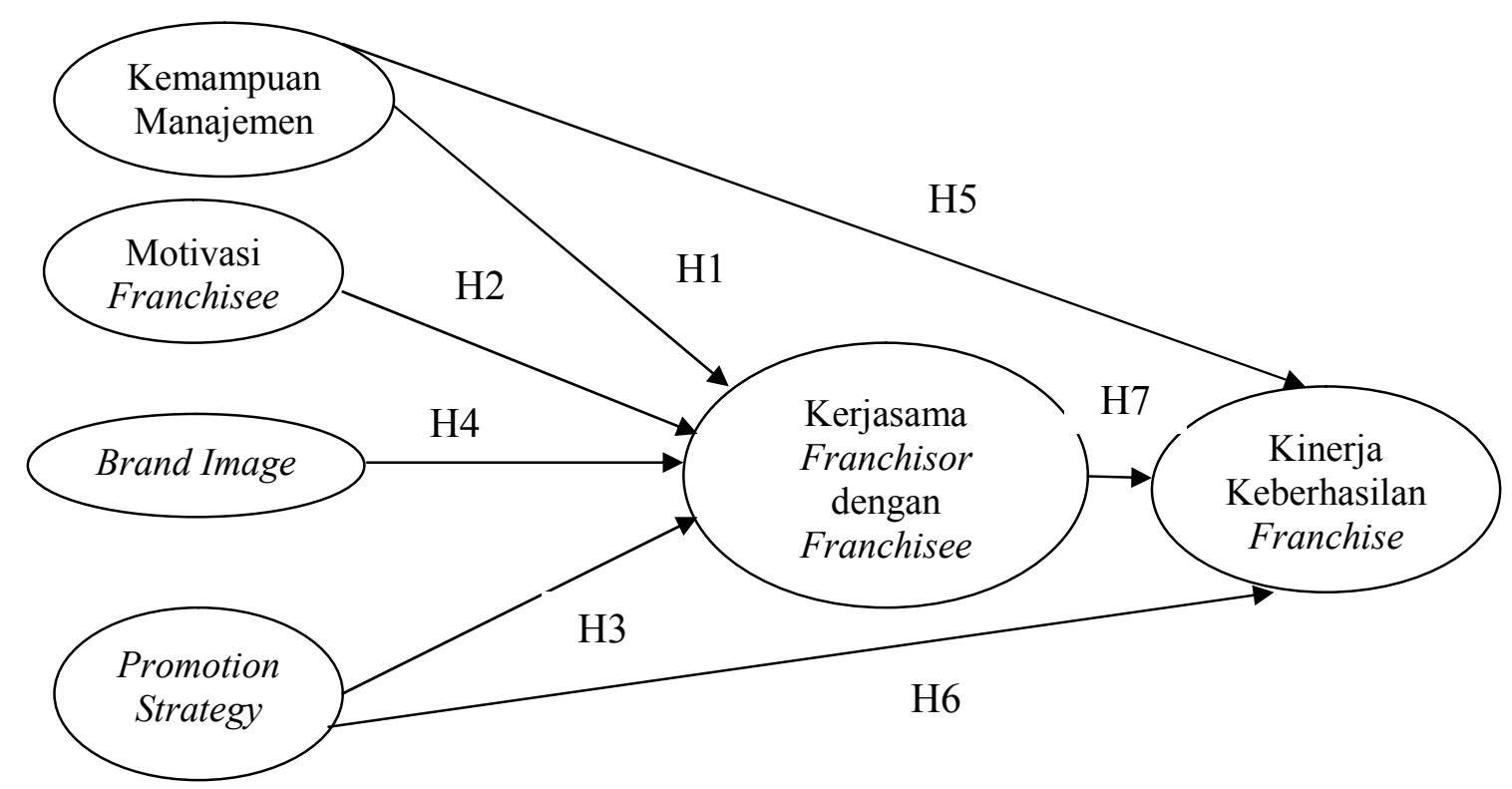

Gambar 2. Kerangka Teori.

Sumber : Monroy dan Alzola, (2005: 585), Grunnhagen dan Mittelstaedt (2005: 207), Pitt, Napoli (2003: 411) Lee dan Khan (1999: 85) ;Morrison (1997 : 39); Hoopkinson dan Scott (1999:827). Greenbaum (2006), Pitt dan Napoli (2003: 411), Scul (1980 dalam Morrison $1997: 39)$

\section{a. Hubungan Kemampuan Manajemen dengan Kerjasama Franchisor dengan Franchisee}

Menurut Morrison (1997 : 39) inovasi manajerial dalam improvisasi peningkatan sinergi dan pembagian sumberdaya agar optimal dalam mengelola franchise diperlukan kualitas kerjasama yang baik. Hubungan kerjasama yang baik antara franchisor dengan franchisee akan sangat menentukan keberhasilan usaha franchise Pada hubungan kerjasama ini sangat penting bagi franchisor untuk dapat menuntun atau mengarahkan franchisee agar dapat menjalankan bisnis franchise-nya secara optimal. Apabila kemampuan manajemen franchise yang dibentuk handal maka dapat men-suport hubungan kerjasama antara franchisor dengan franchisee. Maka apabila ada peningkatan kemampuan manajemen maka akan disertai peningkatan hubungan kerjasama franchisor dengan franchisee. Hipotesis 1: "Semakin tinggi kemampuan manajamen maka akan semakin tinggi hubungan kerjasama antara franchisor dengan franchisee".

\section{b. Hubungan Motivasi Franchisee dengan Kerjasama antara Franchisor dengan Franchisee}

Menurut Hoopkinson dan Scott (1999 : 827) motivasi franchisee sangat berpengaruh terhadap kerjasama antara franchisor dan franchisee untuk membentuk suatu sistem franchise. Sedang Menurut Monroy dan Alzola, (2005 : 585) motivasi franchisee untuk bertindak dalam memilih bisnis franchise dan ikut andil dalam bisnis franchisor adalah karena faktor laba atau profit yang menggiurkan. Berdasar pada penelitian terdahulu tersebut maka semakin tinggi motivasi franchisee dalam mengambil bisnis franchise maka semakin tinggi pula hubungan kerjasama antara franchisor dengan franchisee. Hipotesis 2 : "Semakin tinggi motivasi franchise maka akan semakin tinggi pula hubungan kerjasama antara franchisor dengan franchisee". 


\section{c. Hubungan Promotion Strategy dengan Kerjasama antara Franchisor dengan Franchisee}

Menurut Pitt dan Napoli (2003 : 411) pada hubungan kerjasama antara franchisor dengan franchisee dalam penentuan keberhasilan usaha franchise juga sangat dipengaruhi oleh promotion strategy.

Disini dijelaskan jika semakin bagus strategi promosi yang diterapkan pada masing - masing outlet maka akan meningkatkan hubungan kerjasama antara franchisor dengan franchisee. Hipotesis 3 : "Semakin tinggi atau bagus promotion strategy maka semakin tinggi kerjasama".

\section{d. Hubungan Brand Image dengan Kerjasama antara Franchisor dengan Franchisee}

Menurut Monroy dan Alzola (2005 : 585) menyatakan jika pengelolaan sebuah merk mempunyai keuntungan baik buat franchisor maupun franchisee. Keuntungan buat franchisor adalah untuk keberlanjutan bisnis franchise yang dijalankan, artinya semakin besar brand image sebuah produk franchise maka semakin besar bisnis franchise. Sedang untuk franchisee adalah ikut andil dalam franchise dengan brand yang besar dan terkenal maka menaikkan penjualan yang berimbas pada keuntungan yang meningkat. Hipotesis 4 : "Semakin tinggi brand image maka semakin tinggi hubungan antara franchisor dengan franchisee".

\section{e. Hubungan Kemampuan Manajemen dengan Kinerja Keberhasilan Franchise}

Menurut Helma Marselia (2008) menyatakan bahwa tolak ukur keberhasilan usaha franchise salah satunya adalah manajemen yang handal. Disini dijelaskan jika sebuah manajemen yang baik dan handal mampu menghantarkan keberhasilan suatu usaha franchise. Manajemen dalam hal ini bisa berupa tim yang solid dan tangguh, sistem manajemen yang diterapkan dan sebagainya. Hipotesis 5 : "Semakin tinggi kemampuan manajemen maka kinerja keberhasilan franchise semakin tinggi”.

\section{f. Hubungan Promotion Strategy dengan Kinerja Keberhasilan Franchise}

Menurut chih wen wu (2010:4) mengatakan jika kinerja keberhasilan sebuah usaha franchise adalah terletak pada steategi marketing, dimana marketing adalah merupakan ujung dari penjualan yang merupakan salah satu indikator kebrhasilan franchise. Hipotesis 6: "Semakin tinggi promotion strategy maka semakin tinggi kinerja keberhasilan franchise".

\section{g. Hubungan Kerjasama Franchisor dengan Franchisee dengan Kinerja Keberhasilan Franchise}

Menurut Rosenberg dan Stem, dalam Marisson (1997:39) menyatakan jika konflik yang tinggi antara franchisor dengan franchisee dalam hubungan bisnis franchise mempunyai pengaruh negatif terhadap keberhasilan usaha franchise. Dalam hubungan franchise jika sering terjadi konflik dalam sistem franchise maka bisa dipastikan akan mengganggu ritme kerja bisnis franchise yang berimbas pada menurunnya kinerja keberhasilan franchise. Hipotesis 7 : "Semakin tinggi kerjasama franchisor dengan franchisee maka akan semakin tinggi pula kinerja keberhasilan franchise".

\subsection{Prosedur Penelitian}

Proses penelitian merupakan rencana dan struktur penyelidikan yang dibuat sedemikian rupa agar diperoleh jawaban atas pernyataan - pernyataan penelitian. Rencana ini merupakan rencana menyeluruh dari penelitian mencakup hal - hal yang akan dilakukan peneliti mulai membuat hipotesis dan implikasinya secara operasional sampai kepada analisis akhir data. Suatu desain penelitian menyatakan baik struktur masalah penelitian maupun rencana penyelidikan yang akan dipakai untuk memperoleh bukti empiris mengenai hubungan - hubungan dalam masalah (Mardalis, 2008). 


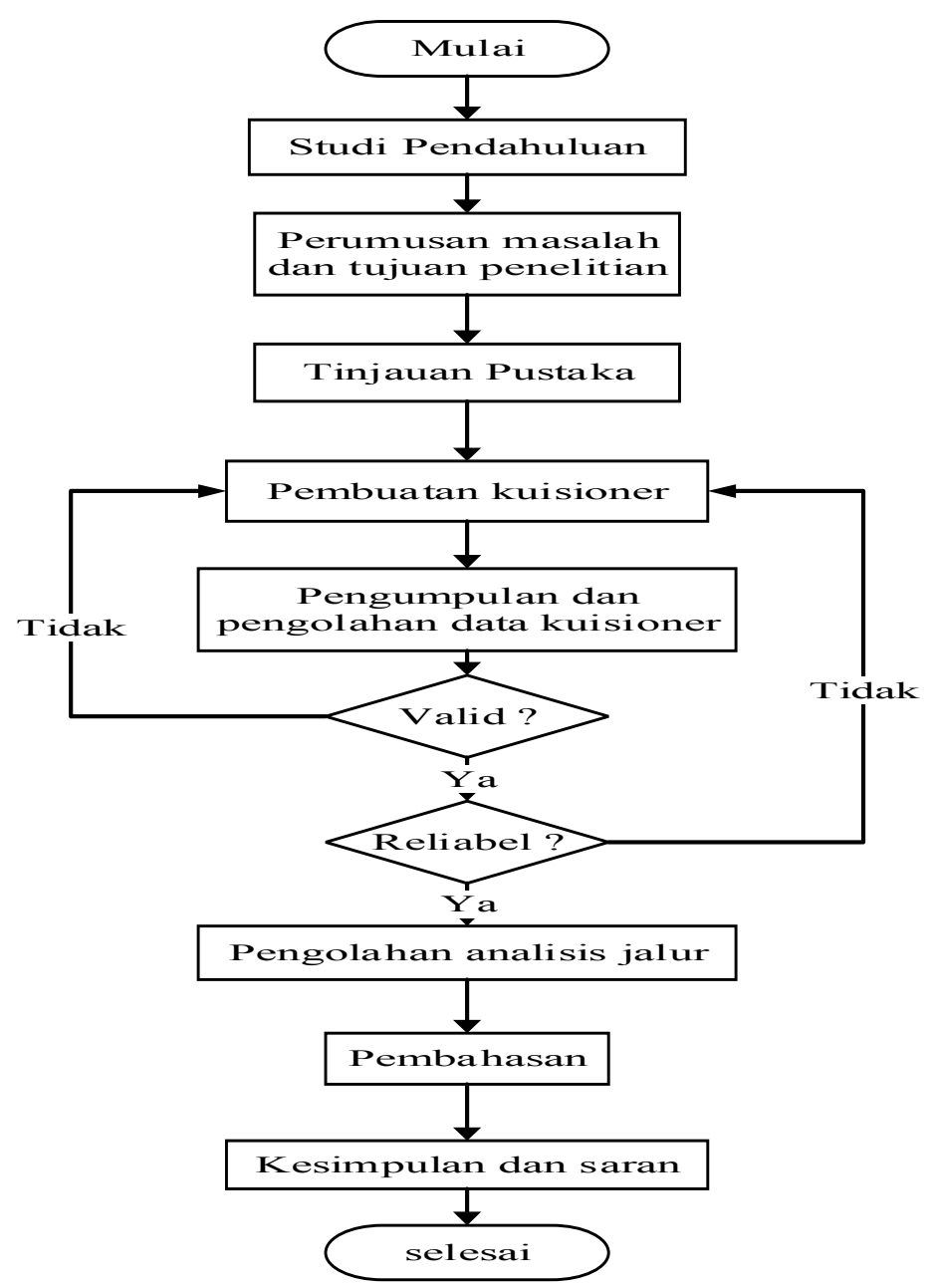

Gambar 3. Alur Penelitian.

Variabel yang digunakan dalam penelitian ini yaitu variabel bebas dan variabel terikat. Variabel terikat adalah kualitas hidup karyawan. Sedangkan variabel bebas adalah organisasi perusahaan dan lingkungan kerja non fisik. Dari variabel penelitian tersebut dapat ditentukan indikator, instrument penelitian dan desain sample yang digunakan.

Langkah selanjutnya adalah mengumpulkan data, baik melalui observasi, wawancara dan penyebaran kuesioner. Data yang telah terkumpul kemudian diolah menggunakan uji validitas dan reliabilitas. Teknik analisa kuantitatif yang digunakan adalah teknik analisis jalur (Path Analysis). Hasil analisa data selanjutnya disajikan serta diinterpretasikan dan langkah terakhir diberi kesimpulan dan saran. Untuk lebih jelasnya rancangan penelitian yang dijabarkan diatas dalam suatu desain rancangan penelitian seperti pada gambar 3 .

\section{HASIL DAN PEMBAHASAN}

Hasil pengujian menunjukkan bahwa model yang digunakan dapat diterima. Tingkat signifikansi sebesar 0,00 menunjukkan sebagai suatu model persamaan struktural yang baik. Kecuali nilai GFI dan AGFI yang yang diterima secara marginal, semua indeks pengukuran TLI, CFI, CMIN / DF, dan RMSEA berada dalam rentang nilai yang diharapkan. AGFI diterima secara marginal, namun AGFI identik dengan $\mathrm{R}^{2}$ pada regresi linier berganda maka nilai AGFI sebesar 0,831 menunjukkan bahwa sumbangan variabel kemampuan manajemen, motivasi Franchise, Brand Image, Promotion Strategy terhadap Kerjasama sebesar 83,1\%, 


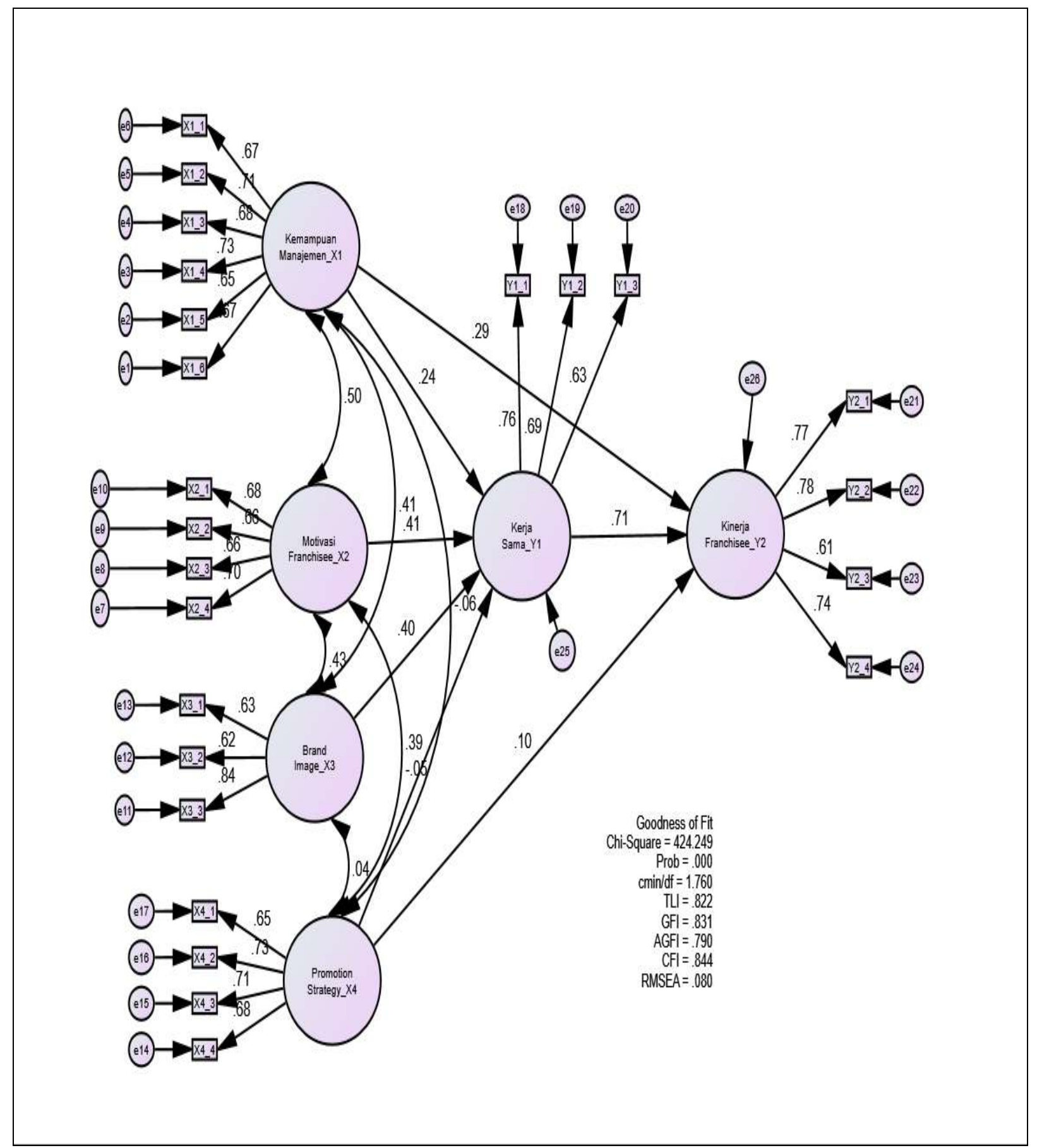

Gambar 4. Pengujian SEM (Structural Equation Modeling).

(Sumber : Data Primer yang Di olah 2017)

sedangkan sisanya dijelaskan oleh variabel variabel lainnya, sehingga dapat dikatakan bahwa nilai AGFI masih cukup tinggi untuk memberikan sumbangan terhadap variasi variabel kinerja Franchise. Dan untuk uji Chi-Square diperoleh nilai 424,249 dengan probabilitasnya 0,00 , yang artinya terdapat pengaruh. Hasil pengujian Structural
Equation Modeling (SEM) disajikan pada gambar 4.

\subsection{Pengaruh Langsung}

Pengaruh langsung adalah pengaruh dari satu variabel bebas ke variabel terikat tanpa melalui variabel dependen lainnya. 


\section{a. Pengaruh Kemampuan Manajemen (X1) terhadap Kerjasama (Y1)}

Hasil uji dengan model SEM menunjukkan bahwa Kemampuan Manajemen (X1) mempunyai nilai estimate sebesar 2,270 dengan tingkat signifikasinya 0,000 artinya bahwa Kemampuan Manajemen (X1) mempunyai pengaruh langsung kepada Kerjasama (Y1). Hal ini didukung oleh penelitian sebelumnya (Altinay \& Brokes, 2012) yang menjelaskan bahwa tipe kontrak dan kemampuan manajemen merupakan faktor utama dalam kerjasama antara franchisor dengan franchisee. Di jelaskan pula bahwa kualitas manajemen yang bagus dari franchisor merupakan nilai jual yang penting pada sebuah perusahaan franchise (Altinay \& Okumus, 2001).

\section{b. Pengaruh Motivasi Franchise (X2) Terhadap Kerjasama (Y1)}

Hasil uji dengan model SEM menunjukkan bahwa Motivasi Franchase (X2) mempunyai nilai estimate sebesar 3,554 dengan tingkat signifikasinya 0,000 artinya bahwa Motivasi Franchise (X2) mempunyai pengaruh langsung kepada Kerjasama (Y1). Hal ini didukung oleh penelitian sebelumnya yang dilakukan oleh (Kim, 2007) yang menyatakan bahwa hubungan teori marketing antar perusahaan yang menjelaskan bagaimana menjadi seorang franchisee yang baik dimana motivasi franchisee yang kuat bisa membuat kerjasama antara franchisor dengan franchisee solid.

\section{c. Pengaruh Brand Image Terhadap Kerjasama (Y1)}

Hasil uji dengan model SEM menunjukkan bahwa Brand Image (X3) mempunyai nilai estimate sebesar 3,725 dengan tingkat signifikasinya 0,000 artinya bahwa Brand Image (X3 mempunyai pengaruh langsung kepada Kerjasama (Y1). Hal ini diperkuat dengan penelitian sebelumnya (Barney, 1991 : Paningua \& Sapena, 2014) yang menyatakan bahwa brand suatu perusahaan sangat berpengaruh terhadap kerjasama antara franchisor dengan franchisee pada perusahaan. Kekuatan brand adalah faktor utama seseorang akan memutuskan untuk mengambil franchise dan menjalin kerjasama dengan perusahaan franchise tersebut. Artinya semakin kuat dan terkenal brand maka semakin banyak peluang untuk terjalinnya kerjasama franchise (Comb \& Ketchen, 1991).

\section{d. Pengaruh Promotion Strategy (X4) Terhadap Kerjasama (Y1)}

Hasil uji dengan model SEM menunjukkan bahwa Promotion Strategy (X4) mempunyai nilai estimate sebesar 4,006 dengan tingkat signifikasinya 0,000 artinya bahwa Promotion Strategy (X4) mempunyai pengaruh langsung kepada Kerjasama (Y1). Hal ini didukung oleh penelitian sebelumnya yang telah dilakukan oleh (Dyer \& Sigh, 1998 : Lewin \& Johnson, 1997) yang hasilnya menyatakan bahwa promotion strategy merupakan salah satu faktor utama dalam kerjasama franchise. Strategi promosi yang gencar dilakukan suatu perusahaan franchise akan semakin memeberikan peluang untuk mendapatkan franchisee lebih banyak sehingga kerjasama atau MoU yang terjadi akan semakin meningkat (Dyer \& Sigh, 1998).

\section{e. Pengaruh Kerjasama (Y1) Terhadap Kinerja Franchise (Y1)}

Hasil uji dengan model SEM menunjukkan bahwa Kerjasama (Y1) mempunyai nilai estimate sebesar 5,305 dengan tingkat signifikasinya 0,000 artinya bahwa Kerjasama (Y1) mempunyai pengaruh terhadap Kinerja Franchise (Y1). Hal ini didukung oleh penelitian yang sudah dilakukan sebelumnya (Dyer \& Sigh, 1998) yang menyatakan bahwa hubungan kerjasama antara franchisee dengan franchisor merupakan faktor utama dalam keberhasilan kinerja franchise. Di sini dijelaskan pula banyaknya kerjasama atau MoU yang terjadi menunjukkan bahwa kinerja perusahaan franchise semakin bagus karena semakin banyak outlet yang dibuka. 


\section{f. Kemampuan Manajemen (X1)}

Hasil uji dengan model SEM menunjukkan bahwa Kemampuan Manajemen (X1) mempunyai nilai estimate sebesar 2,540 terhadap Kinerja Franchise (Y2) denga tingkat signifikasinya 0,011, artinya bahwa Kemampuan Manajemen (X1), secara langsung mempengaruhi terhadap Kinerja Franchise (Y2) karena tingkat signifikasinya $0,011<0,05$. Penelitian sebelumnya yang mendukung hipotesis ini adalah yang dilakukan oleh (Parsa, H,G, 2007) yang menyatakan bahwa kualitas manajemen perusahaan franchise memberikan nilai positif langsung pada kinerja tetapi harus melalui mou atau kerjasama yang dibuat terlebih dahulu. Di jelaskan pula bahwa kualitas manajemen yang bagus dari perusahaan franchise akan menunjukkan kinerja dari perusahaan franchise tersebut.

\subsection{Pengaruh Tidak Langsung}

Pengaruh tidak langsung adalah pengaruh dari satu variabel bebas ke variabel terikat melalui variabel dependen lainnya. Dalam penelitian ini Promotion Strategy (X2).

\section{- $\quad$ Promotion Strategy (X4)}

Hasil uji dengan model SEM menunjukkan bahwa Promotion Strategy (X4) mempunyai nilai estimate sebesar 1,051 terhadap Kinerja Franchise (Y2) dengan tingkat signifikasinya 0,293, artinya bahwa Promotion Strategy (X4), secara langsung tidak mempengaruhi terhadap Kinerja Franchise (Y2), karena tingkat signifikasinya $0,293>0,05$. Hal ini didukung oleh penelitian sebelumnya yang dilakukan oleh (Dandy Fred R, 2003) yang menyatakan bahwa promosi strategi tidak berpengaruh positif pada kinerja perusahaan.
Pada sebuah perusahaan franchise dengan skala menengah, strategi promosi untuk masing - masing wilayah akan berbeda. Strategi promosi yang dijalankan di wilayah pulau Jawa dengan luar Jawa akan berbeda karena kondisi wilayah berbeda pada beberapa faktor misal tingkat pendidikan, struktur geografis (Adi Negara, 2008).

\section{KESIMPULAN}

Dari penelitian yang telah dilakukan dapat ditarik kesimpulan bahwa :

- Variabel yang mempunyai pengaruh langsung pada penelitian ini adalah kemampuaan manajemen terhadap kerjasama, motivasi franchise terhadap kerjasama, pengaruh brand image terhadap kerjasama, pengaruh promotion strategy terhadap kerjasama, pengaruh kerjasama terhadap kinerja franchise dan pengaruh kemampuan manajemen terhadap kinerja.

- Variabel yang tidak mempunyai pengaruh langsung pada penelitian ini adalah promotion strategy terhadap kinerja franchise.

\section{DAFTAR PUSTAKA}

Adi Negara, Uddiyana Bhanda, SH., 2008. Perlindungan Hukum Bagi Franchisor Dalam Perjanjian Waralaba (Franchise Agreement) di Bidang Pendidikan (Studi Kasus Di Lembaga Bimbingan Belajar Primagama). Tesis. Universitas Diponegoro: Semarang.

Altinay, L., \& Brookes, M., 2012. Factors affecting relationship development in international franchise partnerships. Journal of Services Marketing, 26(4), 278-292. 
Altinay, L., Brookes, M., Madanoglu, M., \& Aktas, G., 2014. Franchisees' trust and satisfaction with franchise partnerships. Journal of Business Research, 62(5), 528-534.

Altinay, L., \& Okumus, F., 2010. Franchise partner selection decision making. Service Industries Journal, 30 (6), 929-946.

Barney, J., 1991. Firm resources and sustained competitive advantage. Journal of Management, 17 (1), 99120.

Baron, S, and Schmidt, R., 1991. "Operational aspects of retail franchises". International Journal of Retail and Distribution Management, 19 (2), 13-19.

Chiou, J. S., Hsieh, C. H., \& Yang, C. H., 2004. The effect of franchisors' communication, service assistance, and competitive advantage on franchisees' intention to remain in the franchise system. Journal of Small Business Management, 42 (1), 19-36.

Combs, J. G., \& Ketchen, D. J., 2003. Why do firms use franchising as an entrepreneurial strategy: A metaanalysis. Journal of Management, 29 (4), 443-465.

Combs, J. G., Michael, S. C., \& Castrogiovanni, G. J., 2004. Franchising: $A$ review and avenuesto greater theoretical diversity. Journal of Management, 30 (4), 907.
Dyer, J. H., \& Singh, H., 1998. The relational view: Cooperative strategy and sources of interorganizational competitive advantage. Academy of Management Review, 23 (3),660679.

Dillala, Lisabeth., 2000. Handbook of Multavariate statistic and mathematical modelling. Illinois: Elsevier Science.

Ferdinand, Augusty., 2005. Structural Equation Modeling. Semarang: Badan Penerbit Universitas Diponegoro.

Ferdinand, Augusty., 2006. Metode Penelitian Manajemen. Semarang: Badan Penerbit Universitas Diponegoro.

Ghozali, Imam., 2005. Analisis Multivariat dengan Program SPSS. Edisi ke-3. Semarang : Penerbit UNDIP.

Greenbaum., 2006. "Creating Dynamic Brand awareness", Franchising World, Vol.38 Pg. 46.

Grunhagen, $\quad$ Mittelstaedt., 2005. "Entrepreneur or Investor:Do Multi- Unit Franchisees Have Different Philosophical Orientation?", Journal of Small Business Management, Vol43 pg.207.

Hair, J. F, Black, W. C, Babin, B.J, Anderson, R. E., \& Tatham, R. L., (2006). Multivariate data Analysis. Sixth Edition. New Jersey: Prentice Hall. 
Hopkin, Scott., 1999. "Franchise Relatioship Quality : Micr - Econimic Explanations", European Journal of Marketing, Vol.33 p.827.

Kaufmann, P. J., and Stanworth, J., 1995. "The Decision to Purchase aFranchise: A Study of Prospective Franchisees". Journal of Small Business Management, October, 22-31.

Keller, K. L., 1993. "Conceptualizing, Measuring, and Managing Customerbased Brand Equity". Journal of Marketing, 57 (January), 1-22.

Keller, K. L., 1998. Strategic Brand Management: Building, Measuring, and Managing Brand Equity. Upper Saddle River, NJ: Prentice Hall

Morrison., 1997. How Franchise Job satisfaction and personality affects Performance, organizational commitment, Franchisor Relations, and Intention To Remain, Vol.35,pg.39.

Monroy dan Alzola., 2005. An analysis of Quality Management in Franchise Systems, European Journal Of Marketing Vol.39 p.585.

Kim, C. K., \& Chung, J. Y., 1997. Brand popularity, country image and market share: Anempirical study. Journal of International Business Studies, 28 (2), 361-386.

Lewin, J. E., \& Johnston, W. J., 1997. Relationship-marketing theory in practice: A casestudy. Journal of Business Research, 39 (1), 23-31.

Moch. Basarah dan M. Faiz Mufidin., 2008. Bisnis Franchise dan Aspek - aspek Hukumnya. Bandung: PT Citra Aditya Bakti.
Munizu, Musran., 2010. Pengaruh Faktor faktor Eksternal dan Internal Terhadap Kinerja Usaha Mikro dan Kecil (UMK) di Sulawesi Selatan. Jurnal Manajemen dan Kewirausahaan, Vol.12, No. 1, Maret $2010: 33-41$.

Nawangsari, Albertin Yunita., 2011. Structural Equation Modeling Pada Perhitungan Indeks Kepuasan Pelanggan Dengan Menggunakan Software AMOS (Studi Kasus: Perhitungan Indeks Kepuasan Mahasiswa FMIPA UNY Terhadap Operator IM3). Skripsi. Universitas Negeri Yogyakarta: Yogyakarta.

Norton, S. W., 1988. Franchising, brand name capital, and the entrepreneurial capacity problem. Strategic Management Journal, 9 (2), 105-114.

Pamungkas, Rizki., 2014. Faktor-Faktor yang Mempengaruhi Keberhasilan Usaha Pemegang Usaha Waralaba (Studi Kasus Pada Waralaba Makanan dan Minuman Lokal di Kota Semarang). Universitas Diponegoro Semarang: Semarang.

Peterson, A. and Dant, R., 1990. Perceived Advantages of the Franchise Option from the Franchisees Perceptive: Empirical Insights from a Service Franchise. Journal of Small Business Management, 28 (July), 46-61.

Pitt dan Napoli., 2003. Managing The franchised Brand : The Franchisees 'perspective, Journal of Brand Management, Vol. 10 p.411. 
Park, C. W., Jaworski, B. J., \& MacInnis, D. J., 1986. Strategic brand concept / imagemanagement. Journal of Marketing, 50 (2), 135-145.

Parsa, H.G., 1996. Franchisor - franchisee relationships in quick-service restaurant system. Cornell Hotel and Restaurant Administration Quarterly, 27 (3), 42-49.

Parsa, H. G., 1999. Interaction of strategy implementation and power perceptions in franchise systems: An empirical investigation. Journal of Business Research, 45, 173-185.

Peraturan Pemerintah (PP) RI No. 42 tahun 2007 tentang Waralaba. Jakarta.

.Riyanti, Eko dan Abdul Khoir HS., 2011. Metode Bimbingan Belajar di Primagama (Studi Deskriptif di Lembaga Bimbingan Belajar Primagama). Jurnal Turats, Vol. 7, No. 1, Januari 2011.

Santoso, Singgih., 2007. Structural Equation Modelling: Konsep dan Aplikasi dengan AMOS. Jakarta: PT Elek Media Kompurindo Kelompok Gramedia.

Schul, P.L., 1980. "An Empirical Investigation of the Conflict Behavior Process inFranchise Channels of Distribution," Dissertation Abstracts International (University Microfilm No.41 / 1OA).
Sulistiyani, Endang., 2008. Menangkap Peluang Bisnis Franchise di Indonesia. Jurnal Orbith. VolA No.1 Maret $2008: 64-70$.

Sutedi, Adrian., 2009. Hak Atas Kekayaan Intelektual. Jakarta : Sinar Grafika.

Ulegin, Kabak, Onsel, Ulegin \& Aktas E., 2010. A Problem Structural Model For Analyzing Transportation Enviorement Relationship. European Journal of Operational Risearch, Vol 200, pp 844- 859.

Ulrich, D \& Smallwood, N., 2007. Building a leadership brand. Harvard Business Review, 85 (7/8), 93-100. 